\title{
Metastatic pulmonary calcification in end-stage renal failure
}

\section{Samer Georges MD, Nadim Srour MD MSc}

Competing interests: Nadim Srour has received personal fees from Grifols, Boehringer Ingelheim and Forest Laboratories for activities unrelated to this work. No other competing interests were declared.

This article has been peer reviewed.

The authors have obtained patient consent.

Affiliations: Hôpital Charles-LeMoyne

(Georges), Greenfield Park, Que.; Université de

Sherbrooke (Srour), Sherbrooke, Que.; McGill University (Srour), Montréal, Que.; The Ottawa Hospital Research Institute (Srour), Ottawa, Ont.

\section{Correspondence to:}

Nadim Sour,nadim.srour@ usherbrooke.ca

CMAJ 2016. DOI:10.1503 /cmaj.150778
1 37-year-old man with progressive chronic renal failure (which started in the first year after a kidney transplant 15 years earlier) presented for evaluation of a nonproductive cough. There was no history of dyspnea. The patient was taking calcitriol, prednisone, cyclosporine and azathioprine.

Chest radiography (Figure 1) and thoracic computed tomography (CT) (Appendix 1, available at www.cmaj.ca/lookup/suppl/doi:10.1503/ cmaj.150778/-/DC1) showed extensive ground glass opacities. Bone scintigraphy showed abnormal diffuse pulmonary uptake. Pulmonary function tests showed low-normal lung volumes, with moderately reduced diffusion capacity. Laboratory testing showed calcium 2.52 (normal 2.12-2.52) $\mathrm{mmol} / \mathrm{L}$, phosphate 1.65 (normal $0.80-1.58$ ) $\mathrm{mmol} / \mathrm{L}$ and parathyroid hormone 23.2 (normal 1.6-9.3) pmol/L. Metastatic pulmonary calcification was diagnosed on the basis of the history and imaging. Peritoneal dialysis was started and the patient then underwent kidney transplantation. His cough resolved, and diffusion capacity improved.

Metastatic pulmonary calcification is present in $60 \%-75 \%$ of patients with chronic renal failure on autopsy. ${ }^{1}$ However, it is underrecognized and seldom diagnosed, because chest radiography is not sensitive enough to detect it, and most patients are asymptomatic. ${ }^{2}$ The condition is due to deposition of calcium-phosphate products. ${ }^{2}$ Among those who have symptoms, the manifestations can include progressive dyspnea, hypoxemia, hemoptysis and, rarely, alveolar hemorrhage and fulminant respiratory insufficiency. ${ }^{3}$

The differential diagnosis includes end-stage renal disease, malignancies (such as multiple myeloma) and dystrophic pulmonary calcification (Appendix 2, available at www.cmaj.ca/lookup/ suppl/doi:10.1503/cmaj.150778/-/DC1)., ${ }^{3,4}$

High-resolution CT typically shows poorly defined centrilobular nodules with ground glass opacities $3-10 \mathrm{~mm}$ in diameter. ${ }^{2} \mathrm{CT}$ detects existing calcium deposits that may be inactive, whereas bone scintigraphy identifies areas of active calcium deposition. ${ }^{2}$ Pulmonary function tests often yield

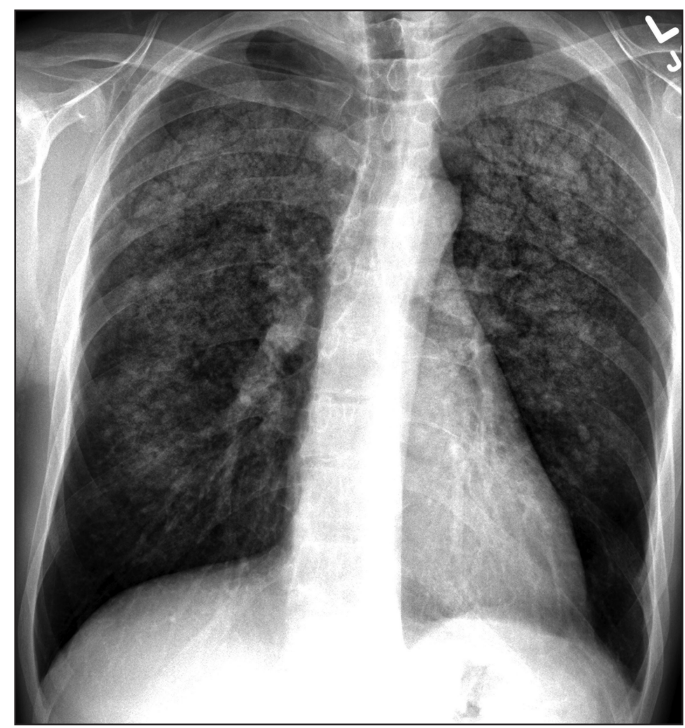

Figure 1: Chest radiograph of a 37-year-old man with chronic renal failure and nonproductive cough, showing ground glass opacities.

normal results, but may show reduced diffusion capacity and a restrictive pattern. ${ }^{3}$

The optimal treatment for metastatic pulmonary calcification remains unknown. Patients with asymptomatic nonprogressive disease may not need any intervention. The mainstay of therapy is normalization of calcium and phosphate biochemistry. ${ }^{3}$ It is unclear whether vitamin D supplementation should be discontinued. ${ }^{3}$ An increase in the frequency of hemodialysis is generally indicated. ${ }^{3}$ Renal transplantation may be considered for eligible patients. Some authors have reported reduction in calcification, but there are also reports of dramatic worsening after transplant. ${ }^{3}$

\section{References}

1. Murris-Espin M, Lacassagne L, Didier A, et al. Metastatic pulmonary calcification after renal transplantation. Eur Respir $J$ 1997;10:1925-7.

2. Cherng SC, Wang YF, Hsu HH, et al. HRCT and bone scintigraphy in end-stage renal failure with metastatic pulmonary calcification. J Med Sci 2006;26:29-32.

3. Belém LC, Zanetti G, Souza AS Jr, et al. Metastatic pulmonary calcification: state-of-the-art review focused on imaging findings. Respir Med 2014;108:668-76.

4. Bendayan D, Barziv Y, Kramer MR. Pulmonary calcifications: a review. Respir Med 2000;94:190-3. 